Research Article

\title{
Granular Bentonite Preparation and Effect of Granulation Behavior on Hydromechanical Properties of Bentonite
}

\author{
Yunzhi Tan $\mathbb{D}^{1},{ }^{1}$ Hui Li $\mathbb{D}^{1},{ }^{1}$ De'an Sun, ${ }^{2}$ and Huajun Ming ${ }^{3}$ \\ ${ }^{1}$ College of Civil Engineering \& Architecture, China Three Gorges University, 8 University Road, Yichang 443002, China \\ ${ }^{2}$ Department of Civil Engineering, Shanghai University, 99 Shangda Road, Shanghai 200444, China \\ ${ }^{3}$ College of Hydraulic \& Environmental Engineering, China Three Gorges University, 8 University Road, Yichang 443002, China
}

Correspondence should be addressed to Hui Li; 201708140021008@ctgu.edu.cn

Received 6 March 2020; Revised 27 August 2020; Accepted 31 August 2020; Published 10 September 2020

Academic Editor: Zaobao Liu

Copyright ( $\odot 2020$ Yunzhi Tan et al. This is an open access article distributed under the Creative Commons Attribution License, which permits unrestricted use, distribution, and reproduction in any medium, provided the original work is properly cited.

Compacted bentonite is regarded as a suitable buffer/backfill material in a high-level radioactive waste disposal repository due to its low permeability, high swelling, and strong adsorption capacity, but the bentonite powder is difficult to compact to a high density only by increasing the compaction energy. Hence, a proposal is made to improve the compactness of bentonite by changing its grain size distribution. To obtain bentonite granules with different sizes, a granulation method is proposed in this paper, in which bentonite powders experience the processes of wetting and drying into plate bentonites, which are then crushed into granules. Furthermore, in this paper, the hydromechanical behavior of granular bentonite is evaluated to verify the feasibility of the method for preparing granules. For this purpose, the granular and original bentonite powder with similar grain sizes were prepared; then, various laboratory tests, including measurements of free swelling ratio, swelling pressure, water retention capacity, and compactness, were carried out. The test results show that the free swelling ratio, swelling pressure, permeability coefficient, and water retention capacity of granular bentonite are almost similar to those of original bentonite, and after compaction, the maximum dry densities of granular and original bentonites are 1.72 and $1.64 \mathrm{~g} / \mathrm{cm}^{3}$ at the optimum moisture content $(20 \%)$ and the energy consumption was reduced by $38 \%$ with the void ratio decreased from 1.30 to 0.8 compared with the original bentonite. It indicates that, compared with the original bentonite, the hydromechanical behavior of granular bentonites changed a little, but its compaction performance has been significantly improved. To investigate the differences in pore size distributions of granular bentonite and original bentonite, MIP and NA tests were performed on samples produced with the wetting-drying agglomerate method, and the results show that the pores with a size of $10.0 \mu \mathrm{m}$ almost disappear and the pores mainly exist with a size of approximately $1.0 \mu \mathrm{m}$. It can be verified that preparing granules by the wetting-drying agglomeration method is feasible, the granulation process has little effect on the hydromechanical properties of bentonite, and after granulation, not only the compactness is improved but also the energy consumption is saved.

\section{Introduction}

Bentonite is a kind of montmorillonite-rich clay, and it is selected as the preferred matrix of buffer/backfill materials in a deep geologic repository for high-level radioactive waste disposal, due to its low permeability, high swelling, and strong adsorption capacity [1-6]. To improve the isolation and impermeability of buffer layers, the bentonite must be compacted into a high-density state. However, bentonite particles are extremely fine after purification. Compared with other clays, bentonite has a relatively concentrated particle size distribution and poor compactness. Some researchers found that the compactness of bentonite is related to the value of compaction pressure and moisture content [7]. Torbjörn et al. [8] carried out the compaction tests on the full-scale bentonite blocks with the block size of $500 \times 571 \times 400 \mathrm{~mm}$, the bulk density of the compacted block reached about $2.0 \mathrm{~g} / \mathrm{cm}^{3}$, and the compaction stress was as high as $50-100 \mathrm{MPa}$ (approximately $5700-14250 \mathrm{kN}$ ). This result reveals that high-powder compaction equipment that can allow vast compaction energy is required if the compacted bentonite needs to reach a high-density state, and the 
method for improving the compactness of bentonite by increasing the compaction pressure is uneconomical, and the energy consumption is very high. Changing the moisture content of bentonite is also a method to improving the compactness, the friction between bentonite particles can be reduced, but some studies found that humidification causes bentonite to swell before compaction, and using mechanical force compaction may not remedy it back to its initial state $[9,10]$. Hence, the method of changing grain size to improve the compactness of bentonite is proposed by authors, and whether the method is feasible needs to be further verified. Therefore, bentonites with different grain sizes need to be prepared.

During the last decades, some studies have reported the methods for preparing the bentonites with different grain sizes, and the prepared products were called pellets. At present, three types of large-scale bentonite (bentonite pellets) preparation methods have been reported: (1) rollercompacted pellets with almond or pillow shapes; (2) extrusion-produced pellets shaped as rods of varying lengths [11]; (3) pressure solid clods or granulated particles of protoliths [12-15], and the grain size of the crushed compacted pellets was about $1-5 \mathrm{~mm}$. The prepared bentonite pellets were intended for filling the gaps between the surrounding rock and bentonite block as well as cracks of the surrounding rocks in the vertical disposal pit $[16,17]$, and they were also used as buffer materials to directly fill the top of the horizontal disposal cell $[18,19]$ due to the advantages of easy manufacturing and emplacing [20, 21].

Due to different purposes, there are also differences in the morphology and size of the bentonite pellets. MX-80 bentonite pellets were used in the French SEALED project, which contains powders and pellets with a mixing ratio of 1 : 4. Among them, the pellets are cylindrical in shape with a diameter of about $7.0 \mathrm{~mm}$ and a height of $7.0 \mathrm{~mm}$. The dried pellets are crushed into powders with a diameter of less than $2 \mathrm{~mm}$, and its average diameter is $D_{50}=0.65 \mathrm{~mm}[22,23]$. Hoffmann et al. [24] prepared bentonite pellets by using powder FEBEX calcium bentonite; the maximum size of the pellet is required to be $1 / 5$ of the smallest size of the compacted specimen powder FEBEX calcium bentonite; meanwhile, the minimum size is specified to be $0.4 \mathrm{~mm}$ to prevent the separation of powder and pellets during the backfill process. Imbert and Villar [25] prepared FoCaRESEAL bentonite pellets (size $25 \times 25 \times 15 \mathrm{~mm}$ ) by a rolling method, and some related tests were carried out on the mixture of pellets and powders with a ratio of $1: 1$ in mass. It can be seen that the preparation of bentonite above was mostly to fill gaps or pores between the bentonite blocks and the host rock in deposition holes. A lot of studies have investigated the hydromechanical performance of pellet/ powder bentonite mixtures and pellets in recent years [26-28], and it was revealed that the suction has an effect on pellet's volume. The hydromechanical performance includes hydraulic and solid mechanical properties; in detail, swelling properties, water retention capacity, compressibility properties, and permeability properties all belong to the range of hydromechanical performance. Guerra et al [29] used X-ray computed microtomography to visualize the infiltration inside the pellet/powder bentonite mixture during hydration and investigated the structural changes of a pellet/powder bentonite mixture upon wetting. Nevertheless, almost all of the abovementioned studies have focused on a single pellet or pellet mixtures and are mainly used as the backfill material. Moreover, the main aim is not to improve the compactness by changing the bentonite granules with special grain sizes.

Therefore, for the purpose of improving the compactness of bentonite, a proposal is made by changing its grain size distribution. Because the existed preparation methods have the disadvantages of high requirements for equipment and lack of the small granule size, in this paper, a granulation method is proposed in which original bentonites experience the process of wetting-drying hardening to form plate bentonites, which are then broken into granules. The size of the granules prepared herein is less than $2 \mathrm{~mm}$, and the size of the pellets is much larger than the granules. Thus, the product obtained by the preparation method in this paper is termed granule. The compaction tests on bentonite granules are carried out to investigate their compactness. After granulation, there are two major changes: (1) the particle size becomes larger and (2) bentonites have undergone one wetting-drying cycle effect. Two key issues need to be demonstrated: (1) whether the wetting-drying cycle has a negative influence on the hydromechanical behavior and (2) whether the compactness is obviously improved through granulation. Hence, the granular and original bentonite powder with similar grain sizes were prepared; then, the indexes measured from the free swelling ratio, swelling pressure, water retention capacity, and compaction tests were chosen to compare the hydromechanical performance of bentonites before and after being granulated.

\section{Testing Material}

The bentonite used in this study is produced in Henan, China. It is floury and delicate and has a white appearance. The montmorillonite content is $82.3 \%$ by the methylene blue method. Other basic properties are listed in Table 1. The X-ray diffraction pattern (Rigaku Ultima IV, Japan) of bentonite is presented in Figure 1.

The results of X-ray fluorescence spectrometry (XRF fluorescence, $\mathrm{XRF}$ ) indicate that bentonite is rich in silicon and aluminum oxide (accounting for $87.1 \%$ ), contains some sodium, iron, potassium, and magnesium oxides, and belongs to sodium bentonite ( $\mathrm{Na}$-bentonite). Its main chemical components and contents in weight are summarized in Table 2 .

\section{Preparation of Bentonite Granules}

Bentonite granules were obtained from the original bentonite powder. The fabrication process is schematically represented in Figure 2. The detailed steps are listed as follows: (1) The original bentonite powder fully swelled after wetting. In detail, $100 \mathrm{~kg}$ of bentonite powder with the initial moisture content of $0 \%$ was weighed and mixed with $328 \mathrm{~kg}$ deionized water according to 1.2 times the liquid limit 
TABle 1: Basic properties of bentonite.

Liquid limit (\%) $\quad$ Plastic limit (\%) $\quad$ Specific gravity Specific surface area $\left(\mathrm{m}^{2} / \mathrm{g}\right) \quad$ Montmorillonite content (\%) $\quad$ Free swelling ratio (\%)

\begin{tabular}{llllll}
\hline 273.6 & 37.5 & 2.76 & 634.8 & 82.3 & 320
\end{tabular}

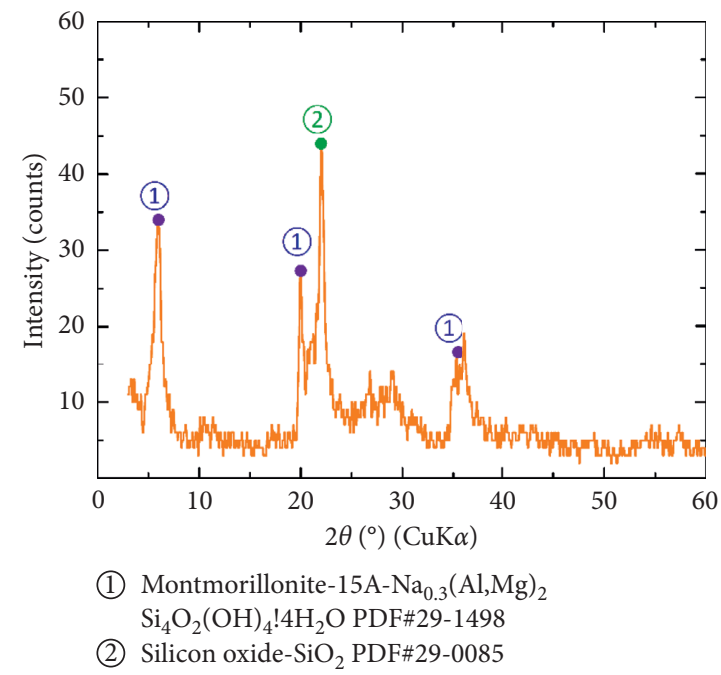

Figure 1: X-ray diffraction pattern of bentonite (radiation source, CuK $\alpha$; wavelength, $0.15406 \mathrm{~nm}$; diffraction angle, from $3^{\circ}$ to $60^{\circ}$; the scanning step, $0.02 \% \mathrm{~min}$ ).

TABle 2: Chemical compositions of bentonite.

\begin{tabular}{lc}
\hline Constituent & Content in weight (\%) \\
\hline $\mathrm{Al}_{2} \mathrm{O}_{3}$ & 15.3 \\
$\mathrm{SiO}_{2}$ & 71.8 \\
$\mathrm{Fe}_{2} \mathrm{O}_{3}$ & 4.5 \\
$\mathrm{MgO}$ & 1.8 \\
$\mathrm{~K}_{2} \mathrm{O}$ & 1.2 \\
$\mathrm{Na}_{2} \mathrm{O}$ & 3.4 \\
$\mathrm{TiO}_{2}$ & 0.5 \\
Others & 1.5 \\
\hline
\end{tabular}

$(273.6 \%)$ in a large basin with a diameter of $1.2 \mathrm{~m}$, and the mixture was stirred evenly. Then, the mixture swelled for 24 hours and finally formed paste-like bentonite. (2) The paste-like bentonite was dried and hardened. To be specific, the paste-like bentonite was paved on a white plastic film and compressed into a flat shape to accelerate dehydration. And the paste-like bentonite with a flat shape was naturally airdried outdoor, and the outdoor temperature is about $40{ }^{\circ} \mathrm{C}$ in summer. After about a week, the water in the flat bentonite was almost completely evaporated; the flat bentonite was dried and hardened. Subsequently, the dry density of the dried flaky bentonite was $1.67 \mathrm{~g} / \mathrm{cm}^{3}$ measured by the waxsealing method. (3) The dried flaky bentonite was crushed into granules. Concretely, the dried flaky bentonite was put into a mechanical crusher and crushed at a speed of $1000 \mathrm{rpm} / \mathrm{min}$ for 25-30 seconds. Generally, the size of the granules is relevant to the duration of crushing, and the longer the crushing time is, the finer the granules are. These above procedures were repeated until all samples were crushed completely. (4) The crushed bentonite samples were divided into granule groups by being sieved with different sizes of 2.0, 1.0, 0.5, 0.25, and $0.075 \mathrm{~mm}$. (5) The granules with different granule groups were weighed and then mixed in proportion for testing according to specific grain size distribution curves. Before mixing, the crushed bentonite granules were dried in the oven at a temperature of $105^{\circ} \mathrm{C}$ for 24 hours. According to the specific grain size distribution curves of the bentonite granules, the mass ratios of the bentonite granules with different granule groups were determined, and then the weight of each granule group was calculated and weighed in accordance with the determined mass ratio.

For original and granular bentonites, the grain size distributions with a grain size greater than $0.075 \mathrm{~mm}$ and less than $0.075 \mathrm{~mm}$ were measured by the sieving method and the laser particle size analysis method (dry method), respectively. The measured results are shown in Figure 3.

It can be seen that the grain size range of the granular bentonite is widened from $0.001-0.25 \mathrm{~mm}$ before granulation to $0.003-2 \mathrm{~mm}$ after granulation. The fraction of granules with grain size larger than $0.075 \mathrm{~mm}$ is remarkably increased from $8.7 \%$ to $87.6 \%$ before and after granulation.

\section{Comparison of the Hydromechanical Performance of Bentonites before and after Granulation}

4.1. Free Swelling Ratio. The free swelling ratio of bentonites is affected by the granule size as well as the wetting-drying cycle history. The granules were broken into powders by a crusher and checked several times through the grain size distribution curve measured by using a laser particle size 


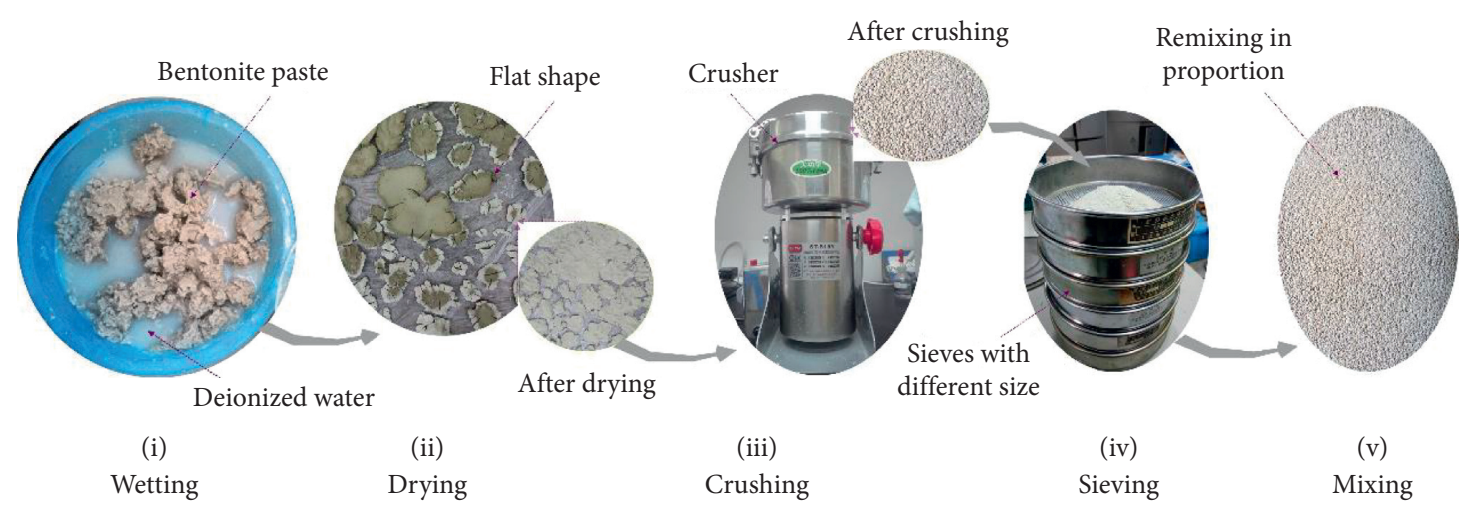

FIgURE 2: The fabrication process of bentonite granules.

analyzer to make the free swelling ratios of granular bentonite (GB) and original bentonite (OB) comparable. When the grain size distribution curve of the granular bentonite was close to that of original bentonites, the crushing process stopped (Figure 4).

The free swelling ratio was calculated by the following equation:

$$
\delta_{\mathrm{ef}}=\frac{V-V_{0}}{V_{0}} \times 100,
$$

where $\delta_{\text {ef }}$ is the free swelling ratio (\%), $V$ is the volume of the sample at full swelling $(\mathrm{ml})$, and $V_{0}$ is the initial volume of the samples $(\mathrm{ml})$.

In accordance with the standard (GB/T 50123-1999, Standard for Soil Test Method) [30], forty-five groups of the free swelling tests were performed on two samples with similar grain sizes in Figure 4. The test results are shown in Figure 5.

By comparison, the free swelling ratio of bentonites before and after granulation is between $270 \%$ and $345 \%$. From a statistical viewpoint, the average free swelling ratio of granular bentonite is $311.2 \%$ with a standard deviation of 0.17 , while the average value for original bentonite is $311.8 \%$ and with a standard deviation of 0.20 . Therefore, granulation has little effect on the free swelling ratio of bentonites with similar grain size distribution curves.

4.2. Constant Volume Swelling Pressure. The bentonites before and after granulation in Figure 4 were oven-dried at $105^{\circ} \mathrm{C}$ to a constant weight, at which the moisture content was regarded as $0 \%$. The target samples with dry densities of 1.36 and $1.60 \mathrm{~g} / \mathrm{cm}^{3}$ were obtained through static compaction in rigid stainless steel molds $(50 \mathrm{~mm}$ in diameter and $10 \mathrm{~mm}$ in height). Compaction pressure was applied to the mold until the maximum pressure $(37.56 \mathrm{MPa})$ was reached, and the maximum pressure was kept for 1 hour. Subsequently, specimens were installed into the dilatometer (Figure 6), and water pressure of $100 \mathrm{kPa}$ from the bottom was applied for saturation under the constant volume. The vertical pressure was recorded during the saturation, and the development of the pressure is shown in Figure 7.

It can be seen from Figure 7 that the maximum pressure (swelling pressure) of the granular bentonite
(GB) is slightly smaller than that of the original bentonite (OB). The larger the dry density is, the greater the difference between them. In addition, permeability tests were continuously performed on specimens after the swelling tests (Figure 6), and the specimens were not replaced. Specifically, when the swelling pressure reached the steady state, the back pressure was increased to $500 \mathrm{kPa}$, the discharged water was collected and measured by an injection syringe, and the saturated permeability coefficient was estimated by the application of a constant water head. When the dry density is $1.60 \mathrm{~g} / \mathrm{cm}^{3}$, the permeability coefficient of the granular bentonite $\left(4.14 \times 10^{-13} \mathrm{~m} / \mathrm{s}\right)$ is slightly smaller than that of the original bentonite $\left(4.35 \times 10^{-13} \mathrm{~m} / \mathrm{s}\right)$, and both are in the order of $10^{-13} \mathrm{~m} / \mathrm{s}$.

Karnland et al. [31] revealed that the swelling pressure of compacted bentonite pellets is slightly greater than that of powdered samples, while the permeability coefficient of the former was greater than the latter. However, Imbert et al. [25] and Hoffmann et al. [24] found that the swelling pressure of compacted bentonite pellets is the same as that of powdered samples with the same dry density, but the permeability coefficient of the granular sample is larger than that of the powdered samples. Therefore, it is still controversial whether the swelling pressure and permeability coefficient of bentonites are the same before and after granulation, which may depend on the stress path, initial compaction state, montmorillonite content, etc.

Despite that, the swelling pressure and permeability coefficient measured in this paper have satisfied the design requirements in the repository for buffer materials with a swelling pressure greater than $1.0 \mathrm{MPa}$ and a permeability coefficient less than $10^{-12} \mathrm{~m} / \mathrm{s}$ (refer to [2]). Noticeably, there is no "collapse" phenomenon (the dotted frame in Figure 7), which is similar to that of original bentonites in the swelling curve of granular bentonite. The "collapse" phenomenon can be explained in detail by Hoffmann et al. [24], Sun et al. [32], and Lee et al. [33]. During the granulation process, bentonite experienced the processes of wetting, swelling, drying, hardening, etc., possibly changing the microstructure of the bentonite and redistributing its pore structures. Therefore, the swelling pressure of granular bentonites did not fluctuate with elapsed time. 


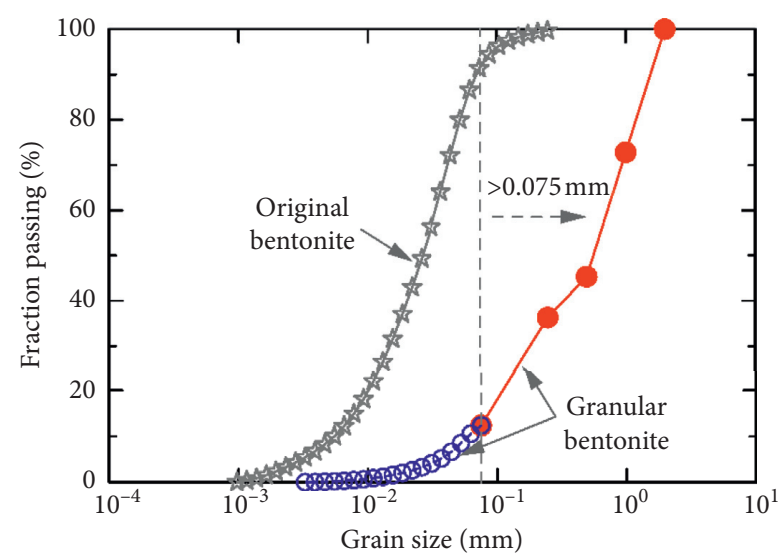

FIGURE 3: Grain size distribution curves before and after granulation.

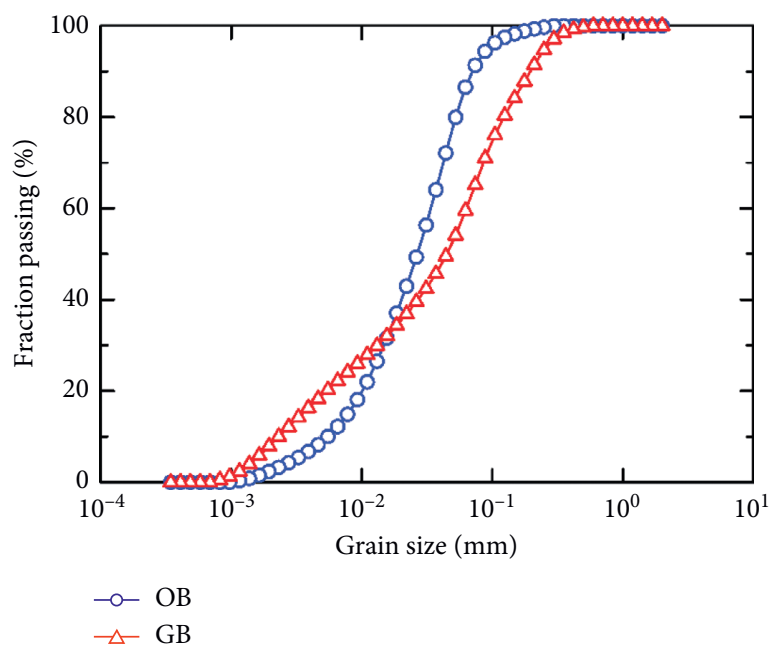

FIGURE 4: Grain size distribution curves of original and granular bentonites with similar grain sizes.

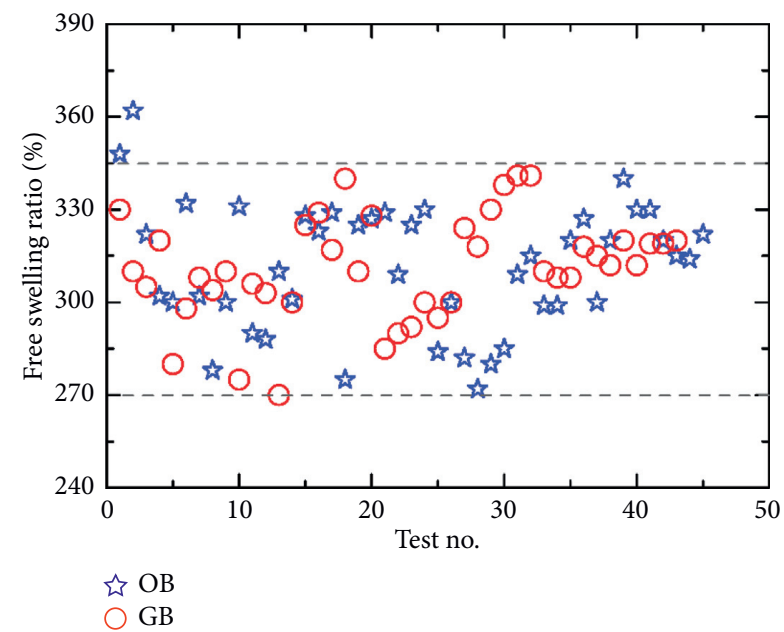

FIGURE 5: Free swelling ratios of original and granular bentonites.

4.3. Water Retention Capacity. The bentonite samples in Figure 4 were taken, and the original and granular bentonites were compacted into a round pie shape with a diameter of
$61.8 \mathrm{~mm}$ and a thickness of $10 \mathrm{~mm}$. The initial moisture content is $0 \%$, and the dry density is $1.36 \mathrm{~g} / \mathrm{cm}^{3}$. The details to prepare the compacted bentonite are similar as mentioned in Section 4.2. The samples were saturated by deionized water under constant volume for four days. After that, the saturated samples were weighed at first and then transferred to a desiccator containing a saturated salt solution at the bottom, and three parallel samples were placed for each salt solution. The weight of each sample was tracked per two weeks. When the weight of the sample is constant twice in succession, it is considered that the suction equilibrium was reached. It took approximately 60 days to reach equilibrium at a constant temperature of $25^{\circ} \mathrm{C}$. The type of salt solution, relative humidity, and corresponding suction value are shown in Table 3. Among them, the type of salt solution and the relative humidity at $25^{\circ} \mathrm{C}$ are obtained from ASTM standards [34].

After the suction equilibration, the round pie samples were weighed and the gravitational moisture content was calculated. Considering the volume shrinkage caused by drying, the sample volume was also measured by the waxsealing method, and then the volumetric moisture content or 


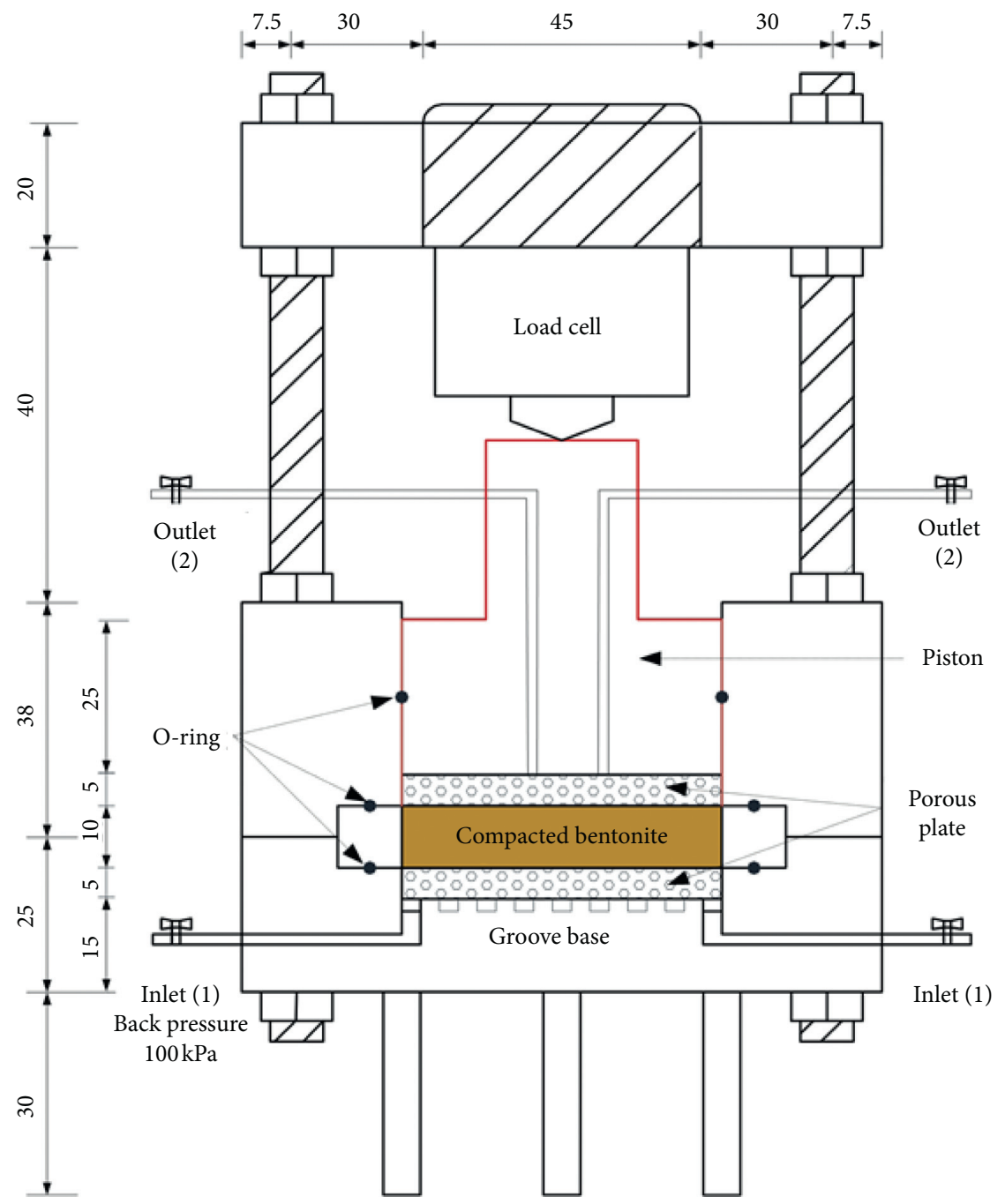

FIGURE 6: Schematic of the device for testing constant volume (swelling pressure) (unit: $\mathrm{mm}$ ).

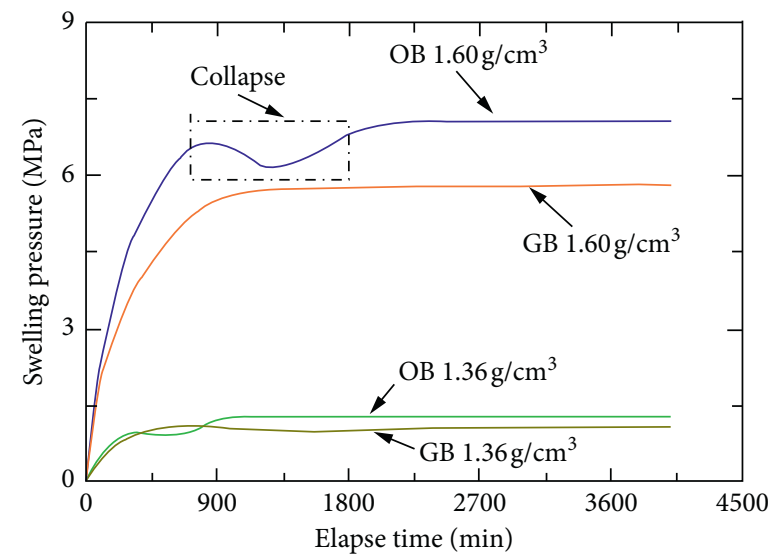

FIGURE 7: Evolution of swelling pressure of original and granular bentonites.

degree of saturation was calculated. The water retention curves of compacted bentonites before and after granulation are shown in Figure 8.
Figure 8(a) shows that after granulation, the moisture content was slightly affected. Figure $8(\mathrm{~b})$ reveals that the degree of saturation was gradually decreased with the 
TABLE 3: Type of salt solution, relative humidity, and corresponding suction value $\left(25^{\circ} \mathrm{C}\right)$.

\begin{tabular}{lcc}
\hline Salt & Relative humidity (\%) & Suction (MPa) \\
\hline $\mathrm{K}_{2} \mathrm{SO}_{4}$ & 97.3 & 3.76 \\
$\mathrm{KCl}$ & 84.2 & 23.61 \\
$\mathrm{NaCl}$ & 75.3 & 38.95 \\
$\mathrm{KI}$ & 68.9 & 51.15 \\
$\mathrm{NaBr}$ & 57.6 & 75.74 \\
$\mathrm{~K}_{2} \mathrm{CO}_{3}$ & 43.2 & 115.24 \\
$\mathrm{MgCl}_{2}$ & 32.8 & 153.06 \\
$\mathrm{CH}_{3} \mathrm{COOK}$ & 22.5 & 204.81 \\
$\mathrm{LiCl}$ & 11.3 & 299.37 \\
\hline
\end{tabular}

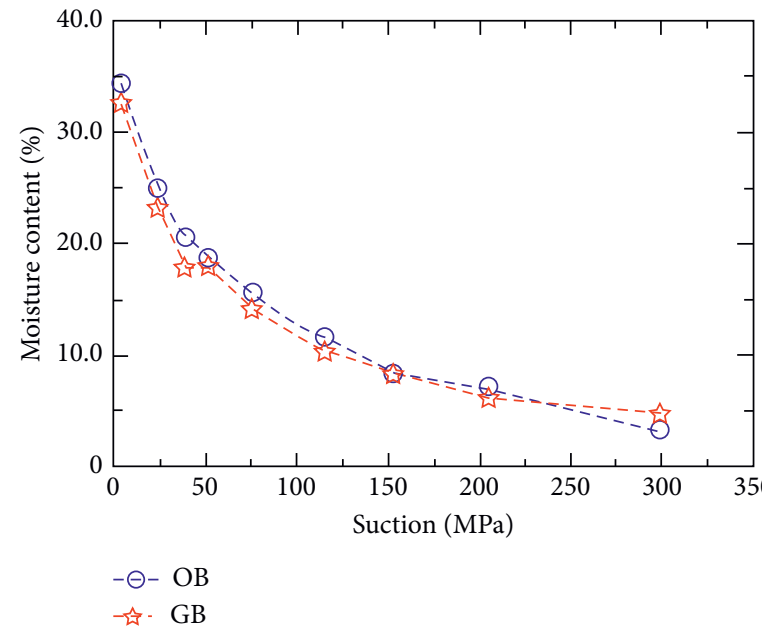

(a)

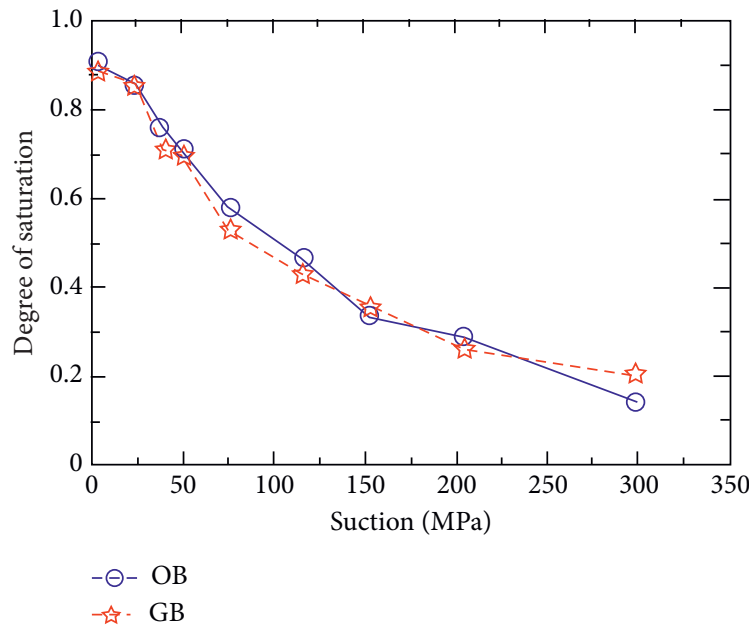

(b)

FIGURE 8: Water retention curves in the dehydrating process. (a) Moisture content against suction curves and (b) degree of saturation against suction curves.

increase of suction. However, even if the suction reaches to $300 \mathrm{MPa}$, the degree of saturation is still maintained at about $15 \%$ for bentonites, which shows that bentonite has a considerable ability to absorb water. Moreover, as shown in Figure 8 , the drying water retention curves of bentonites before and after granulation are almost the same, indicating that granulation can hardly affect its water retention capacity.

4.4. Scanning Electron Microscope Photograph. The bentonite samples in Figure 4 were taken, and the original and granular bentonites were oven-dried at $105^{\circ} \mathrm{C}$ to a constant weight; then the scanning electron microscope (SEM) photographs were carried out, respectively. The SEM photographs of bentonites before and after granulation are shown in Figure 9. It can be seen that the phenomenon of bentonite agglomerate is more obvious after granulation, and it becomes a microgranule with a size of $10 \mu \mathrm{m}$. Meanwhile, there are distinguished boundaries between different granules (Figure 9(b)). However, the microgranules of original bentonite have a loose arrangement (Figure 9(a)), and some tactoids have a scattered distribution in the adjacent. It can be found that granular bentonite, combined with the grain size distribution curve of the granules, is a mixture of not less than the size of the microgranules.

4.5. Pore Response to Swelling and Contraction Behavior. Preparing granules implies that the bentonite has undergone one wetting-drying cycle. Bentonite swells freely once it is soaking and then shrinks after drying in the air. Whether the granules are dense due to the shrinkage affects the subsequent compression effect. And whether the granular bentonite swells due to reimmersion represents its self-healing ability.

Referring to the multiscale structure model of bentonite granules proposed by Sauzéat et al. [35], the structural characteristics of bentonite granules are known as follows. The basic unit of bentonite is a TOT sandwich layer formed by two silicon-oxygen tetrahedron $(\mathrm{T})$ with one aluminaoxygen octahedral $(\mathrm{O})$ in the middle. Layers and layers were stacked together and the clay platelet structure was formed. The space distance between the layers is about a few angstroms $(1 \mathrm{~nm}=10 \AA)$, and the nonmovable adsorbed water and ionized water are mostly filled between the layers. The clay platelet structure is superimposed on a tactoid. Then, the tactoids overlap each other to form a microaggregate. 


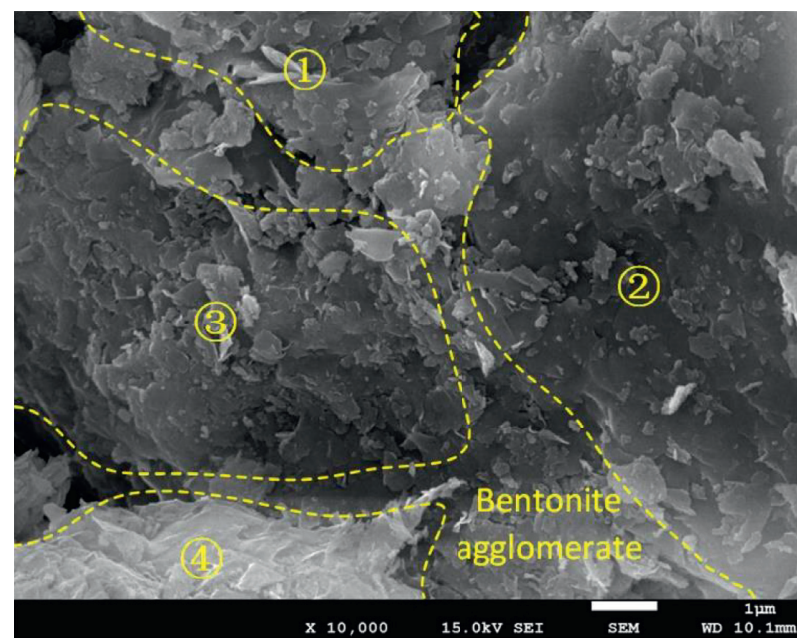

(a)

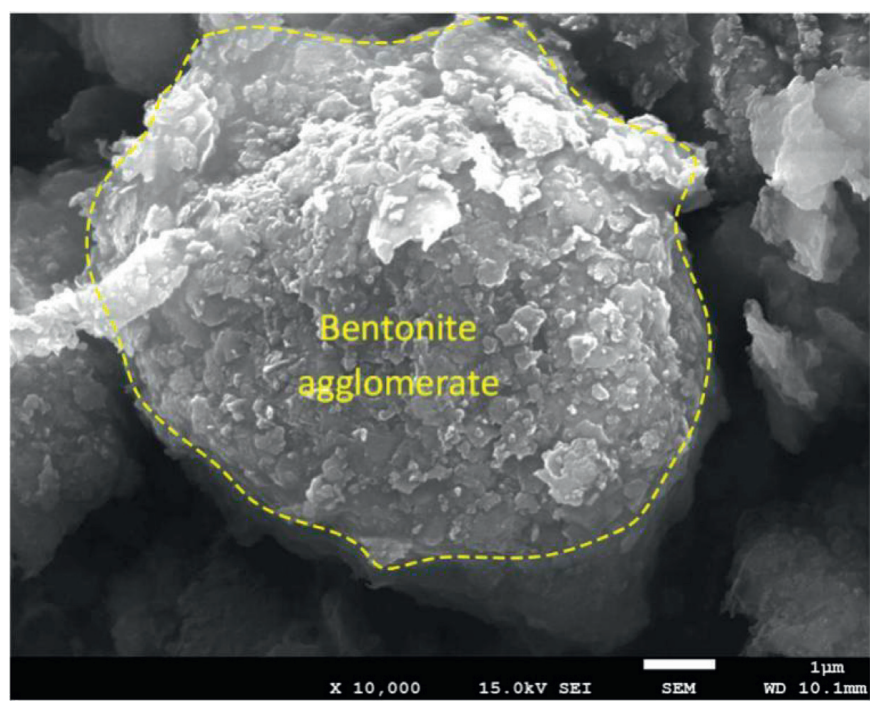

(b)

FIGURE 9: SEM photographs of original and granular bentonites. (a) Original bentonite (X10000) and (b) granular bentonite (X10000).

The pore size between the microaggregates is less than $20 \mathrm{~nm}$, which belongs to microporosity. Microaggregates are polymerized with each other to form microgranules with a diameter of about $10 \mu \mathrm{m}$, and these microgranules bond together to form an agglomerate, and the pores between microgranules belong to the mesoporosity.

The pore size distribution (PSD) of bentonite was measured by the mercury intrusion porosimetry (MIP) tests and nitrogen adsorption (NA) tests. All bentonite samples for the MIP were pretreated by the liquid nitrogen freezedrying method, which can effectively minimize the pore volume change caused by the drying; therefore, the obtained PSD can represent the actual situation. In addition, two repetitions of the bentonite samples for MIP tests were performed to avoid statistical deviations. The PSD curves of original bentonite experiencing free swelling (OB-S) and free swelling-drying (OB-SD) are presented in Figure 10.

It can be observed that substantial amounts of pores were formed in the pasty original bentonite after free swelling (Figure 10(a)), whose PSD is mainly concentrated at about $10 \mu \mathrm{m}$ (Figure 10(b)). But the pore volume after the swellingdrying is significantly reduced (Figure 10(a)), and the PSD is mainly concentrated at about $0.05 \mu \mathrm{m}$ (Figure 10(b)). With respect to the classification of pores, various methods and standards have been proposed; some representative studies can refer to Sing et al [36], Romero et al [37], and Sun et al. [38]. Typically, Sing et al. proposed a pore classification standard that the micropore size is less than $2 \mathrm{~nm}$, the macropore size is more than $50 \mathrm{~nm}$, and the mesopore size is midway between them [36]. In light of this, most pores of the bentonite experiencing the swelling-drying are mesopores and macropores.

To investigate the PSD of original and granular bentonites due to reimmersion, the bentonite samples in Figure 4 were taken, and they were wetted by absorbing water to be in the free swelling status. Then the MIP tests were performed. The PSD curves of original bentonites in the free swelling status (OB-S) and granular bentonites in the free swelling status (GB-S) are shown in Figure 11. As can be seen from the figure, the pore volume formed by swelling after the granular bentonite absorbed the water increased (Figure 11(a)), compared with the original bentonite. Majority of the pore sizes are concentrated at about $1.0 \mu \mathrm{m}$, while the sizes of the original bentonite are mainly concentrated at about $10 \mu \mathrm{m}$ (Figure 11(b)). It can be noticed that the macropores decreased.

Both Hoffmann et al. [24] and Guerra et al. [22] found that bentonite granules include two types of pores: mesopores and macropores of the agglomerate. It was found that the mesopore sizes were mainly concentrated at about $13 \mathrm{~nm}$, while the macropore sizes were concentrated at about $3.0 \mu \mathrm{m}$. Figure 10 shows that, after the complete swellingdrying in the air, most pore sizes were concentrated at about $0.05 \mu \mathrm{m}$. This implied that denser bentonite granules could be obtained by using the wetting-drying method.

Nevertheless, due to the agglomeration of granular bentonite, a "transient stability state" structure was formed. There are many large pores, and they swell freely after the soaking. Therefore, a false phenomenon occurred; the pore volume after the swelling of the reinfiltration was much larger than that of original bentonites. This fact cannot be understood, as granulation has improved the swelling capacity. However, it can be inferred that the granular bentonite still has excellent swelling capacity after the reinfiltration.

It is not difficult to find that the PSD range only covers a pore size greater than $0.01 \mu \mathrm{m}(10 \mathrm{~nm})$ attributed to the limitation of the pore size range of MIP tests. However, given the fact that the intertactoid pore size is usually less than $20 \mathrm{~nm}$, and the PSD in this range needs to be measured by the NA tests. The PSD of granular bentonite after the air shrinkage is shown in Figure 12. 


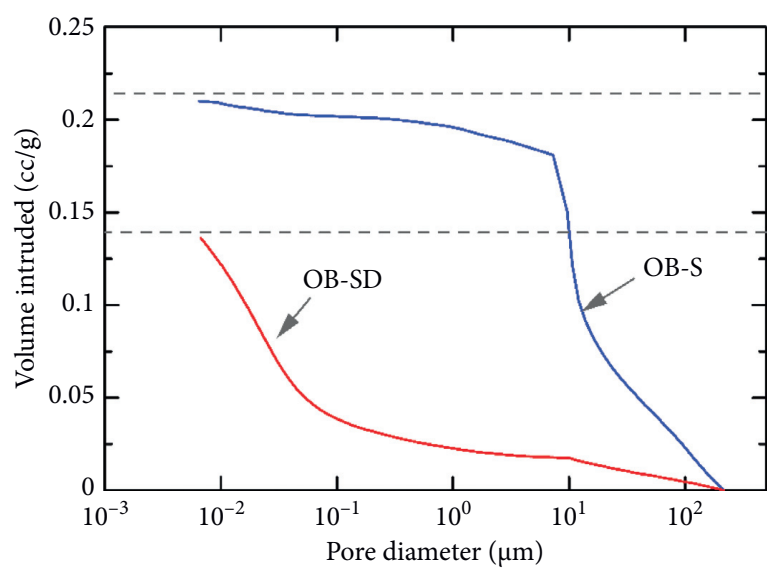

(a)

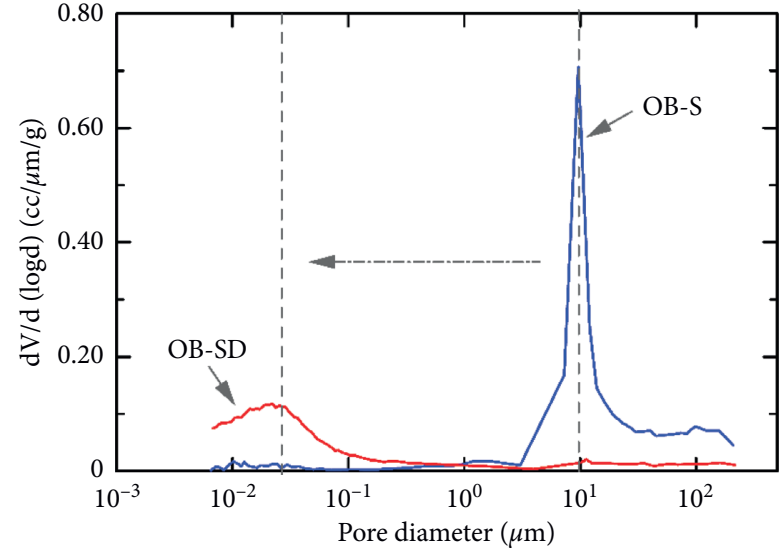

(b)

FIGURE 10: PSD of original bentonite samples at paste state (OB-S) and subsequent drying (OB-SD) by MIP. (a) Cumulative pore volume and (b) PSD density.

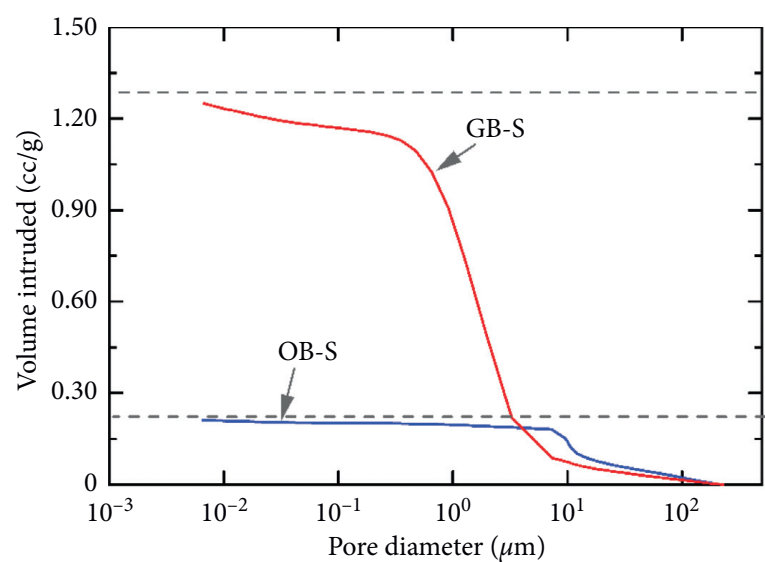

(a)

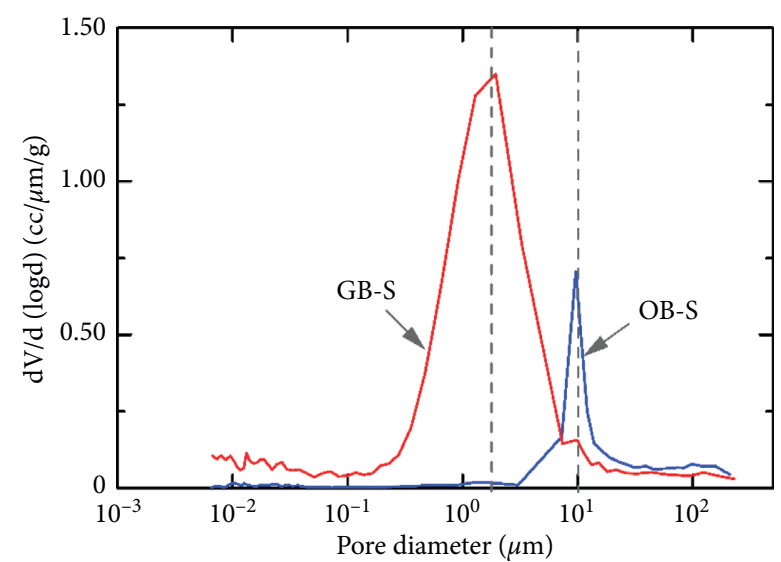

(b)

FIGURE 11: PSD of original and granular bentonites at pasty state by MIP. (a) Cumulative pore volume and (b) PSD density.

Figure 12 shows that one wetting-drying cycle in the granulation process has negligible influences on micropores with a pore size of less than $6 \mathrm{~nm}$ (Figure 12(a)), and it can be inferred that the interlayer pores remain nearly unchanged. However, the pore size corresponding to peaks of the PSD curves of bentonites before and after granulation is shifted from $18 \mathrm{~nm}$ to $12 \mathrm{~nm}$ (Figure 12(b)), and the total pore volume is slightly reduced (Figure 12(a)), indicating that shrinkage may have occurred.

\section{Compaction Performance Evaluation of Granular Bentonites}

5.1. Compaction Performance. The static compaction tests on the original bentonite and granular bentonite samples in Figure 4 were performed with a maximum compaction pressure of $37.56 \mathrm{MPa}$ and a compacted rate of $0.1 \mathrm{~mm} / \mathrm{min}$, and the compaction curves are shown in Figure 13.

Both the optimum moisture contents of the granular bentonite and original bentonite are about $20 \%$, but the maximum dry density of the former $\left(1.72 \mathrm{~g} / \mathrm{cm}^{3}\right)$ is greater than that of the latter $\left(1.64 \mathrm{~g} / \mathrm{cm}^{3}\right)$, indicating that granulation can improve the compactness. The samples obtained by compaction are small-scale samples (diameter $39.1 \mathrm{~mm}$ ), the frictional resistance between the soil particles and the compacting mold is large, and the pressure value provided by the compacting equipment is too small, resulting in a limited increase in the dry density of granular bentonite. In addition, the pressures required for the granular and original bentonites with the optimum moisture content to reach a dry density of $1.60 \mathrm{~g} / \mathrm{cm}^{3}$ (refer to Liu et al. [39] for the value of bentonite buffer material in the test) are 19.41 and $31.15 \mathrm{MPa}$, respectively. After granulation, the energy consumption is reduced by nearly $38 \%$.

The sample was slowly and evenly humidified to the target value $\left(w_{\text {opt }}\right)$ by using an air humidifier, and the actual moisture contents of the original bentonite sample and granular bentonite sample were $19.6 \%$ and $20.0 \%$, respectively. Hereafter, the samples were placed in the mold and statically compacted to an initial void ratio of 1.30 by a 


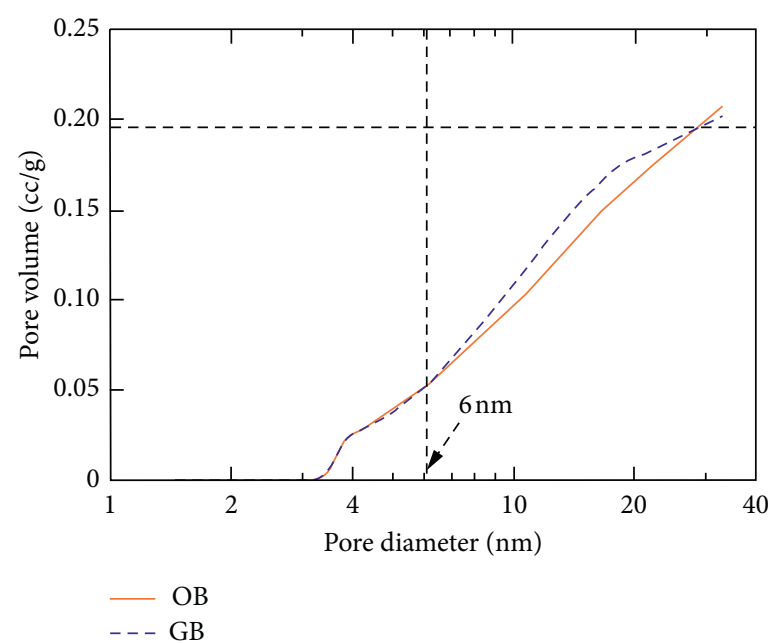

(a)

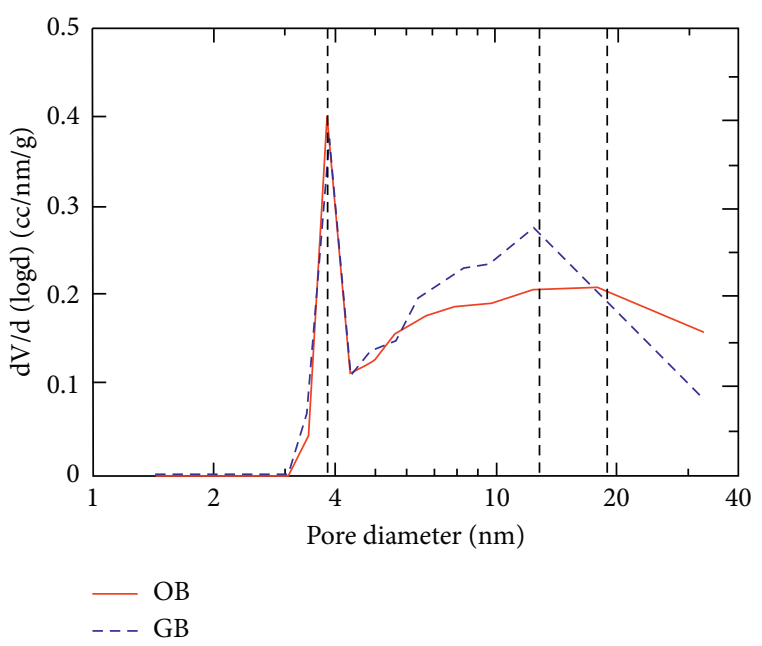

(b)

FIGURE 12: PSD of original and granular bentonites by NA. (a) Cumulative pore volume and (b) PSD density.

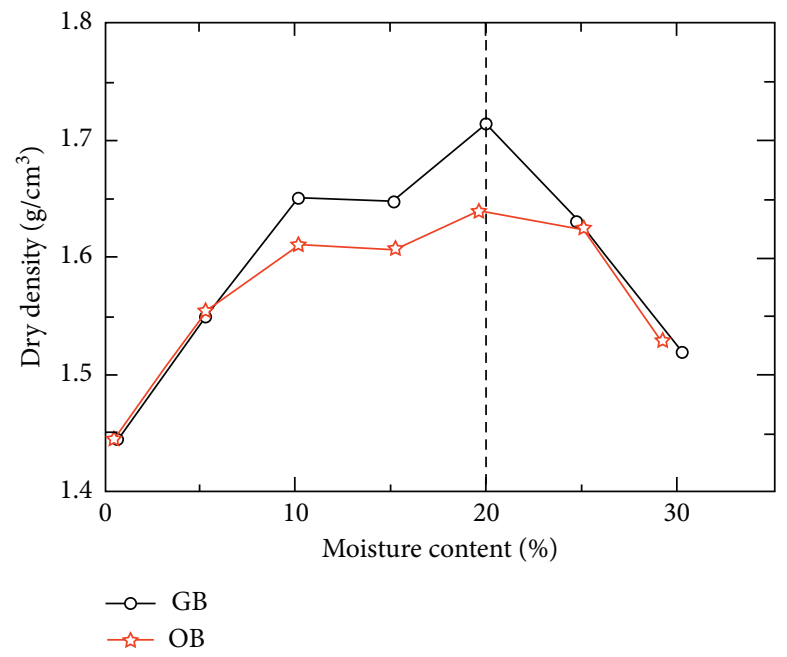

FIgURE 13: Compaction curves of original and granular bentonites.

pressure machine, which was regarded as the initial state of the specimens. After the compaction, the compression tests on the specimens with an initial void ratio of 1.30 were performed, and the variation of the void ratio with the compression pressure is shown in Figure 14.

As shown in Figure 14(a), the void ratio of the granular bentonite is smaller than that of the original bentonite with the same initial moisture content at the equivalent compression pressure. With the void ratio decreased from 1.30 to 0.8 , the compression pressure for the granular bentonite is about $14 \mathrm{MPa}$, whilst it is approximately $22 \mathrm{MPa}$ for original bentonite. This indicates that the granular bentonite is more energy efficient when the same compression effect is required. Of course, the initial moisture content is also a key factor affecting compression. As shown in Figure 14(b), the granular bentonite specimens with the optimum moisture content are easier to compress, and more energy is consumed under the dry condition. In addition, once the compaction pressure exceeds $10 \mathrm{MPa}$, the granular bentonite specimens with the high moisture content are difficult to compress, no matter how much the pressure increases. It can be seen that, after granulation, the proper moisture content can significantly improve the compression efficiency.

5.2. Pore Size Change due to Compactness. After the compaction tests, additional PSD tests were performed on compacted bentonite (GB) samples prepared at moisture contents of $10 \%$ and $20 \%$. They are shown in Figure 15. Figure 15(a) indicates that the GB sample with the initial moisture content of $20 \%$ has a smaller cumulative pore volume and is relatively dense. It can be seen from Figure 15(b) that the macropore size of bentonite samples with moisture contents of $10 \%$ and $20 \%$ are mainly concentrated at 0.68 and $0.20 \mu \mathrm{m}$, respectively. In addition, the mesopore size of the samples is always maintained at 


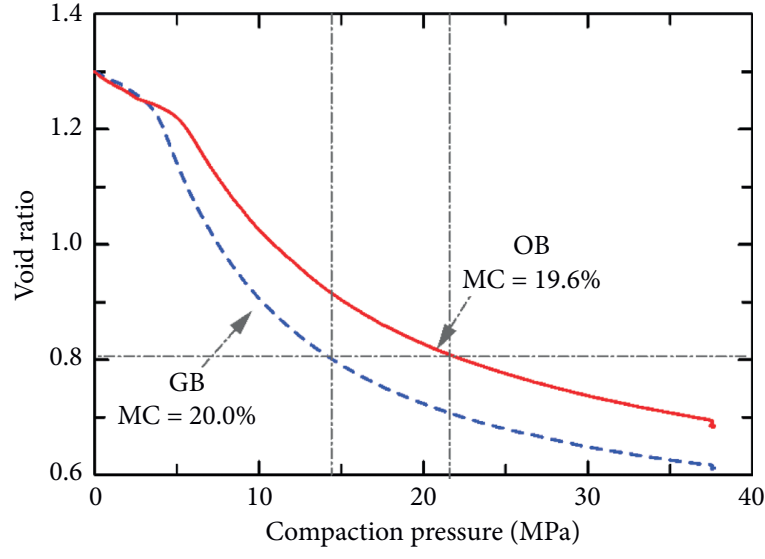

(a)

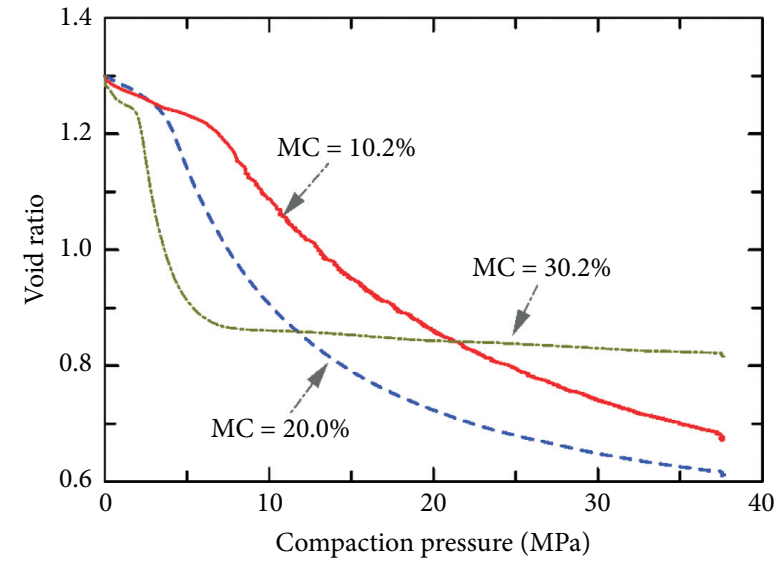

(b)

FIgURE 14: Compression curves. (a) Original and granular bentonites with the same initial void ratio and moisture content (MC). (b) Granular bentonite with the same initial void ratio and different moisture contents.

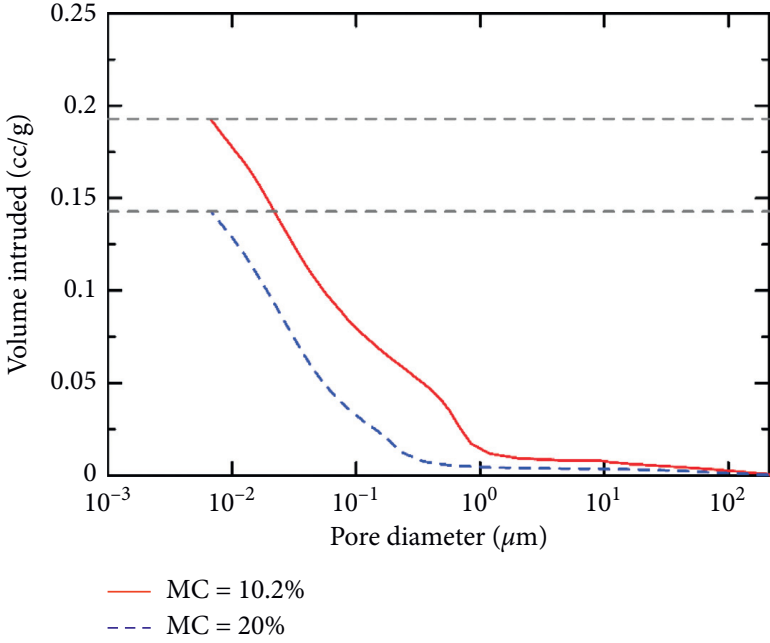

(a)

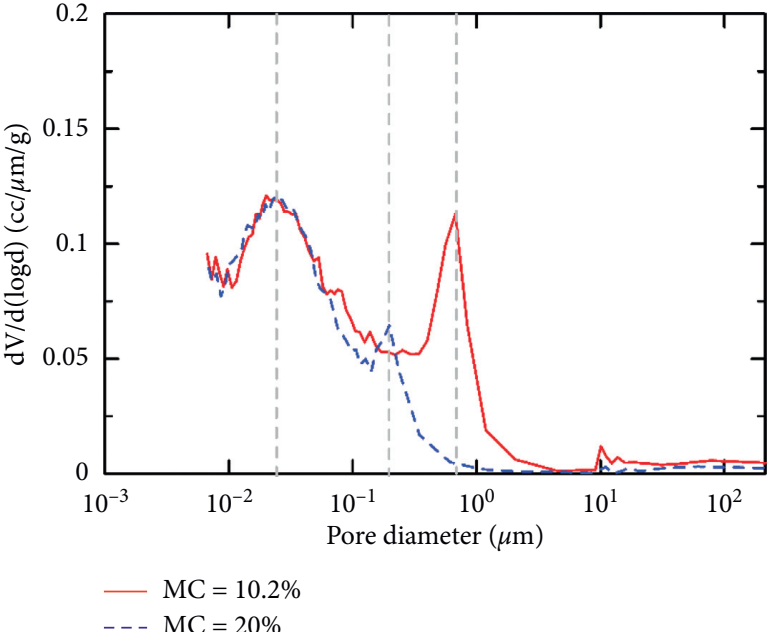

(b)

FIGURE 15: PSD of granular bentonite with the same initial void ratio and different moisture contents. (a) Cumulative pore volume and (b) PSD density.

$0.02 \mu \mathrm{m}$. By increasing the initial moisture content, the pore size of the macropores between the granules is reduced, but the mesopores are less affected.

It can be seen that the initial moisture content, combined with the test results in Figure 14(b), has a great influence on the compaction effect. When the initial moisture content is low, sufficient pressure is required to overcome the intergranular resistance to compress the pores. Therefore, controlling the moisture content to a reasonable value (optimum moisture content) can reduce the macropore size in the soil and the fraction of macropores, thereby achieving the purpose of improving the compaction performance.

\section{Conclusions}

In this paper, a granulation method for preparing bentonite granules with different grain sizes was proposed, compared with the existing methods, and the grain size of the prepared granules is not limited, especially for preparing small granules with a grain size of less than $2 \mathrm{~mm}$. And a series of the free swelling ratio, swelling pressure, water retention capacity, static compaction, and pore size distribution analysis tests were performed. The effect of bentonite samples before and after granulation on the hydromechanical behavior was comparatively investigated. Based on the test results and discussions, the following conclusions can be drawn:

(1) The granular bentonite underwent a wetting-drying cycle, which has little effect on the free swelling ratio, permeability coefficient, and water retention capacity but has some influence on the swelling pressure.

(2) Although the granulation method includes a wetting-drying cycle, it only has an influence on pore sizes of more than $6 \mathrm{~nm}$ and does not change the interlayer spacing of the montmorillonite. After the 
bentonite freely swells, the granules formed by drying are apparently dense and the pores are mainly the mesopores.

(3) After the granulation of bentonite, not only the compactness is improved but also the energy consumption is saved. At the optimum moisture content (20\%), the energy consumption was reduced by $38 \%$ compared with the original bentonite, and the maximum dry densities of granular and original bentonites are 1.72 and $1.64 \mathrm{~g} / \mathrm{cm}^{3}$, respectively. The compaction performance of granules has been significantly improved; especially, the energy consumption is greatly saved. For the specimens with large sizes, saving the compaction pressure using the granular bentonite is more obvious.

\section{Data Availability}

All the data presented in the figures and tables in the manuscript were obtained from laboratory tests at China Three Gorges University. And the data used in this work are available from the corresponding author upon request.

\section{Conflicts of Interest}

The authors declare that there are no conflicts of interest regarding the publication of this paper.

\section{Authors' Contributions}

All authors approved the manuscript for publication.

\section{Acknowledgments}

The work described was financially supported by the National Natural Science Foundation of China (no. 51979150), the Foundations from the Key Laboratory of Geological Hazards on Three Gorges Reservoir Area (no. 2018KDZ05), and the Youth Innovation Team Project of Hubei Province (T201803).

\section{References}

[1] J. Wang, W. M. Chen, R. Su, Y. H. Guo, and Y. X. Jin, "Geological disposal of high-level radioactive waste and its key scientific issues," Chinese Journal of Rock Mechanics and Engineering, vol. 25, no. 4, pp. 801-812, 2006, in Chinese.

[2] R. Pusch, Geological Storage of Highly Radioactive Waste, Springer, Berlin, Germany, 2008.

[3] W. M. Ye, Y. G. Chen, B. Chen, Q. Wang, and J. Wang, "Advances on the knowledge of the buffer/backfill properties of heavily-compacted GMZ bentonite," Engineering Geology, vol. 116, no. 1-2, pp. 12-20, 2010.

[4] SKB, Long-term Safety for the Final Repository for Spent Nuclear Fuel at Forsmark, Technical Report TR-11e01, SKB, Stockholm, Sweden, 2011.

[5] Posiva, Safety Case for the Disposal of Spent Nuclear Fuel at Olkiluoto. Performance Assessment 2012, Report Posiva 201204, Springer, Berlin, Germany, 2013.

[6] T. Wei, D. Hu, H. Zhou, J. Lu, and T. Lü, "Influences of degree of saturation and stress cycle on gas permeability of unsaturated compacted Gaomiaozi bentonite," Engineering Geology, vol. 254, pp. 54-62, 2019.

[7] G. Ma, H. Zhang, and Z. Su, "Compressibility of four types of granular bentonite materials," Proceedings of the 8th International Congress on Environmental Geotechnics, vol. 2, pp. 317-325, 2018.

[8] S. Torbjörn, A. Linus, and J. Victor, System Design of Backfill: Full Scale Production Test of Backfill Blocks, Svensk Kärnbränslehantering AB, Stockholm, Sweden, 2015.

[9] W.-j. Sun, Z.-f. Wei, D.-a. Sun, S.-q. Liu, B. Fatahi, and X.-q. Wang, "Evaluation of the swelling characteristics of bentonite-sand mixtures," Engineering Geology, vol. 199, pp. 1-11, 2015.

[10] S. M. Rao and K. Ravi, "Influence of initial degree of saturation on swell pressures of compacted Barmer bentonite specimens," Annals of Nuclear Energy, vol. 80, pp. 303-311, 2015.

[11] A. Linus and S. Torbjörn, Optimization of Backfill Pellet Properties: ÅSKAR DP2 Laboratory Tests, Svensk Kärnbränslehantering $\mathrm{AB}$, Stockholm, Sweden, 2012.

[12] H. Wimelius and R. Pusch, Backfilling of KBS-3V Deposition Tunnels-Possibilities and Limitations, Svensk Kärnbränslehantering AB, Stockholm, Sweden, 2008.

[13] T. Sandén and L. Börgesson, Deep Repository-Engineered Barrier System. Piping and Erosion in Tunnel Backfill. Laboratory Tests to Understand Processes during Early Water Uptake, Svensk Kärnbränslehantering $\mathrm{AB}$, Stockholm, Sweden, 2008.

[14] Z. Zhang, W. M. Ye, Z. R. Liu, Q. Wang, and Y. J. Cui, "Mechanical behavior of GMZ bentonite pellet mixtures over a wide suction range," Engineering Geology, vol. 264, p. 105383, 2019.

[15] Z.-R. Liu, Y.-J. Cui, W.-M. Ye, Z. Zhang, Q. Wang, and B. Chen, "Investigation on vibration induced segregation behaviour of crushed GMZ bentonite pellet mixtures," Construction and Building Materials, vol. 241, p. 117949, 2020.

[16] P. Keto, D. Dixon, D. Gunnarsson, E. Jonsson, L. Börgesson, and J. Hansen, Assessment of Backfill Design for KBS-3V Repository, Svensk Kärnbränslehantering AB, Stockholm, Sweden, 2009.

[17] Z. Zhang, W.-M. Ye, Z.-R. Liu, B. Chen, and Y.-J. Cui, "Influences of PSD curve and vibration on the packing dry density of crushed bentonite pellet mixtures," Construction and Building Materials, vol. 185, pp. 246-255, 2018.

[18] M. Plötze and H. P. Weber, Esdred: Emplacement Tests with Granular Bentonite $M x-80$, National Cooperative for the Disposal of Radioactive Waste, Wettingen, Switzerland, 2007.

[19] C. D. Bock, J. M. Bosgiraud, H. Weber et al., "Achievements of the ESDRED project in buffer construction technology," in Proceedings of Euradwaste' 08 Conference, Luxembourg, Europe, October 2008.

[20] A. M. Guerra, Y. J. Cui, N. Mokni et al., "Investigation of the hydro-mechanical behaviour of a pellet/powder MX80 bentonite mixture using an infiltration column," Engineering Geology, vol. 243, pp. 18-25, 2018.

[21] A. M. Guerra, P. Delage, Y. J. Cui et al., "Water retention properties and microstructure changes of a bentonite pellet upon wetting/drying; application to radioactive waste disposal," Géotechnique, vol. 70, pp. 1-41, 2019.

[22] A. M. Guerra, N. Mokni, P. Delage et al., "In-depth characterisation of a mixture composed of powder/pellets MX80 bentonite," Applied Clay Science, vol. 135, pp. 538-546, 2017.

[23] N. Mokni, M. A. Guerra, Y. J. Cui et al., "Modelling the longterm hydro-mechanical behaviour of a bentonite pellet/ 
powder mixture with consideration of initial structural heterogeneities," Géotechnique, vol. 70, pp. 1-61, 2019.

[24] C. Hoffmann, E. E. Alonso, and E. Romero, "Hydro-mechanical behaviour of bentonite pellet mixtures," Physics and Chemistry of the Earth, Parts A/B/C, vol. 32, no. 8-14, pp. 0-849, 2007.

[25] C. Imbert and M. V. Villar, "Hydro-mechanical response of a bentonite pellets/powder mixture upon infiltration," Applied Clay Science, vol. 32, no. 3-4, pp. 197-209, 2006.

[26] Z. Zhang, W. M. Ye, and Z. R. Liu, "Investigation of swelling behaviors of GMZ bentonite pellet mixtures," Japanese Geotechnical Society Special Publication, vol. 7, no. 2, pp. 239-243, 2019.

[27] Z. R. Liu, Y. J. Cui, W. M. Ye, B. Chen, Q. Wang, and Y. G. Chen, "Investigation of the hydro-mechanical behavior of GMZ bentonite pellet mixtures," Acta Geotechnica, vol. 32, 2020.

[28] A. M. Guerra, Y. J. Cui, Y. He et al., "Characterization of water retention, compressibility and swelling properties of a pellet/ powder bentonite mixture," Engineering Geology, vol. 248, pp. 14-21, 2019.

[29] M. A. Guerra, P. Aimedieu, M. Bornert et al., "Analysis of the structural changes of a pellet/powder bentonite mixture upon wetting by X-ray computed microtomography," Applied Clay Science, vol. 165, pp. 164-169, 2018.

[30] Ministry of Water Resources of the People's Republic of China, Standard for Soil Test Method, Ministry of Water Resources of the People's Republic of China, Beijing, China, (in Chinese), 1999.

[31] O. Karnland, U. Nilsson, H. Weber, and P. Wersin, "Sealing ability of Wyoming bentonite pellets foreseen as buffer material - laboratory results," Physics and Chemistry of the Earth, Parts $A / B / C$, vol. 33, no. sup.1, pp. S472-S475, 2008.

[32] D. A. Sun, H. B. Cui, and W. J. Sun, "Swelling of compacted sand-bentonite mixtures," Applied Clay Science, vol. 43, no. 34, pp. 485-492, 2009.

[33] J. O. Lee, J. G. Lim, I. M. Kang, and S. Kwon, "Swelling pressures of compacted Ca-bentonite," Engineering Geology, vol. 129-130, pp. 20-26, 2012.

[34] ASTM, Standard Practice for Maintaining Constant Relative Humidity by Means of Aqueous Glycerin Solutions, ASTM, West Conshohocken, PA, USA, 2015.

[35] E. Sauzéat, D. Guillaume, A. Neaman et al., "Caractérisation minéralogique, cristallochimique et texturale de l'argile MX80," Report ANDRA C RP OLEM 01-001, Springer, Berlin, Germany, (in French), 2001.

[36] K. S. W. Sing, D. H. Everett, R. A. Haul et al., "Reporting physisorption data for gas/solid systems with special reference to the determination of surface area and porosity (Recommendations 1984)," Pure and Applied Chemistry, vol. 57, no. 4, pp. 603-619, 1985.

[37] E. Romero and P. H. Simms, "Microstructure investigation in unsaturated soils: a review with special attention to contribution of mercury intrusion porosimetry and environmental scanning electron microscopy," Geotechnical and Geological Engineering, vol. 26, no. 6, pp. 705-727, 2008.

[38] H. Sun, D. Mašín, J. Najser, V. Neděla, and E. Navrátilová, "Bentonite microstructure and saturation evolution in wetting-drying cycles evaluated using ESEM, MIP and WRC measurements," Géotechnique, vol. 69, no. 8, pp. 713-726, 2019.

[39] Y. M. Liu, J. Wang, S. F. Cao et al., "A large-scale THMC experiment of buffer material for geological disposal of highlevel radioactive waste in China," Rock and Soil Mechanics, vol. 34, no. 10, pp. 2756-2789, 2013, (in Chinese). 